\title{
Lung adenocarcinoma initially mimicking localized emphysema
}

\author{
Jiahan Cheng ${ }^{1,2 \#}$, Jiandong Mei ${ }^{1,2 \#}$, Qiang Pu${ }^{1,2}$, Lunxu Liu ${ }^{1,2}$ \\ ${ }^{1}$ Department of Thoracic Surgery, West China Hospital, Sichuan University, Chengdu 610041, China; ${ }^{2}$ Western China Collaborative Innovation \\ Center for Early Diagnosis and Multidisciplinary Therapy of Lung Cancer, Sichuan University, Chengdu 610041, China \\ \#These authors contributed equally to this work. \\ Correspondence to: Lunxu Liu. Department of Thoracic Surgery, West China Hospital, Sichuan University, No. 37, Guoxue Alley, Chengdu 610041, \\ China. Email: lunxu_liu@aliyun.com.
}

\begin{abstract}
Here we report an exceedingly rare case of gradual continuous radiographic changes in lung cancer over five years. Over this period, the lesion was initially diagnosed as localized emphysema, yet in the final year, revealed itself to be a solid malignant nodule. Then the patient underwent thoracoscopic left upper lobectomy, followed by systematic lymphadenectomy when the nodule was confirmed as adenocarcinoma. This study demonstrates that slowly localized emphysema should be continuously monitored closely given its potential for malignant transformation in high-risk patients.
\end{abstract}

Keywords: Lung adenocarcinoma; emphysema

Submitted Sep 12, 2019. Accepted for publication Dec 27, 2019.

doi: $10.21037 /$ tcr.2020.01.29

View this article at: http://dx.doi.org/10.21037/tcr.2020.01.29

\section{Introduction}

Cavitary pulmonary lesions are commonly encountered during chest radiography, and differential diagnoses include diverse benign and malignant diseases (1). A thin-walled lung cavity is usually considered to be a benign lesion. Although many lung cancer patients may present with thick-wall cavities, the patients with gradual growing thinwalled cavities which mimicking localized emphysema are exceedingly rare.

\section{Case presentation}

A 65-year-old man was admitted to the thoracic surgery department due to an asymptomatic solid pulmonary nodule in the left upper lobe (Figure 1). The nodule was detected by annual chest computed tomography (CT) screening one month prior to admission. After reviewing his previous CT scans, the lesion presented as a bulla five years ago on his first chest CT scan (Figure 2). The bulla slowly enlarged during the following annual CT scans, and finally transformed to a pure solid nodule by his last chest CT scan one year ago (Figure 3). The patient reported no history of malignancy, thoracic trauma or allergies but noted a 45- year smoking history of 20 cigarettes per day. There were no abnormalities on physical examination at admission. His blood tests including tumor markers were normal. Following systemic assessment, surgery was performed. He underwent thoracoscopic left upper lobectomy, followed by systematic lymphadenectomy when the nodule was confirmed as adenocarcinoma through frozen histology. Postoperative pathological examination confirmed this diagnosis (Figure 4).

\section{Discussion}

Generally, early lung adenocarcinoma presents as groundglass nodule, mixed ground-glass nodule or solid nodule on CT imaging (2). In this case, however, the lung adenocarcinoma presented as a thin-walled cavity, initially mimicking localized emphysema. Several studies suggest that there is a relationship between the wall thickness of pulmonary cavity and malignancy (3-6). A maximum wall thickness of $4 \mathrm{~mm}$ or less on CT is considered to be a benign disease, while a wall thickness greater than $15 \mathrm{~mm}$ has a tendency to develop malignant diseases (4). Thick-walled cavitary adenocarcinoma has poor 


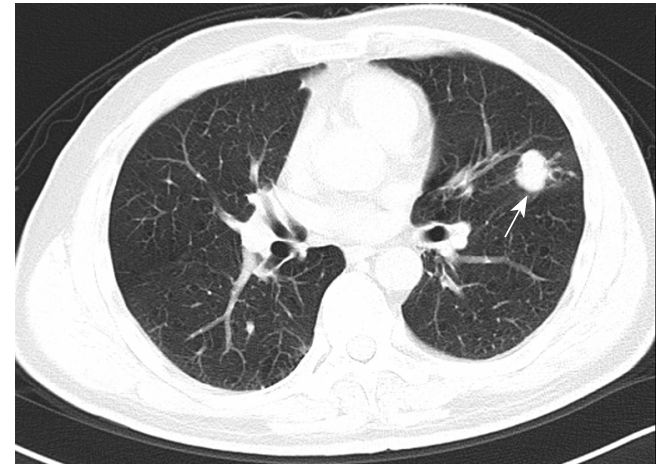

Figure 1 A 65-year-old man had adenocarcinoma (arrow head) in the left upper lobe which mimicking localized emphysema at initiation.

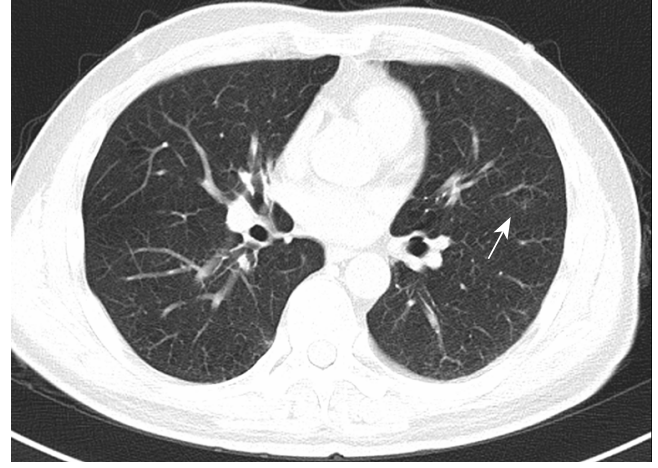

Figure 2 The lesion presented as a bulla (arrow head) five years ago on his first chest CT scan.
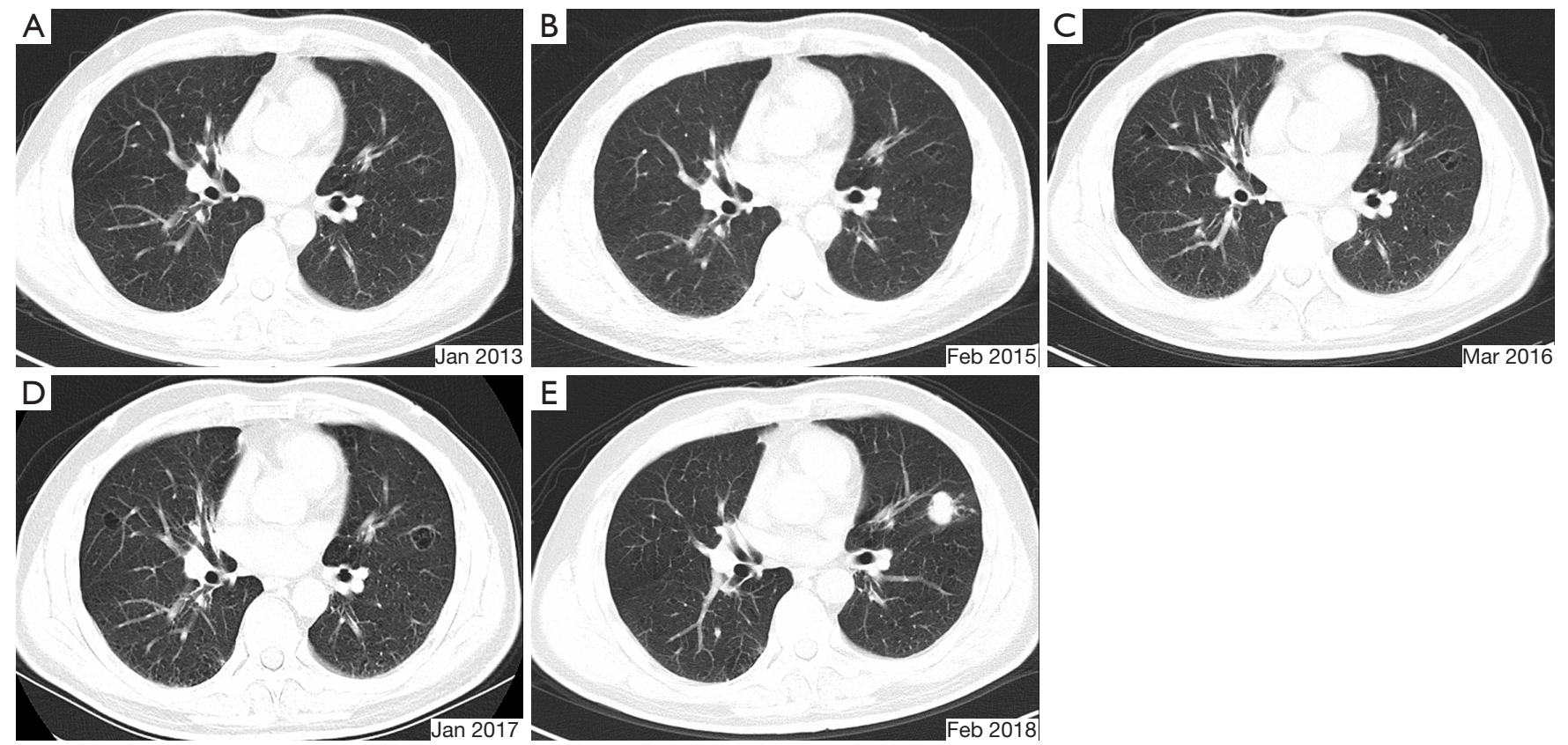

Figure 3 Annual computer tomography showed the progression of localized emphysema (arrow head) revealing itself to be solid nodule in six years.

prognostic characteristics compared with thin-walled cavitary adenocarcinoma, especially in the early stage (5). Other radiological features that may also have diagnostic implications for malignant cavities are inner- and outer-wall margins, as well as increased growth of the cavity over time.

Thin-walled cavitary lesions are frequently observed in benign pulmonary diseases, such as chronic obstructive pulmonary diseases (COPD), chronic pulmonary aspergillosis and tuberculosis. In malignancies, pulmonary cavitation is commonly caused by insufficient blood supply to the central part of the lesion and formation of a necrotic core (7). Cavities with diverse shapes and uneven thick walls are always found in squamous cell lung cancer and occur in tumors larger than $3 \mathrm{~cm}$. In the present case, the patient showed a thinner cavity wall, which resembled localized emphysema for five years. The lesion was originally diagnosed as a product of COPD.

Another essential clinical parameter for evaluating the 


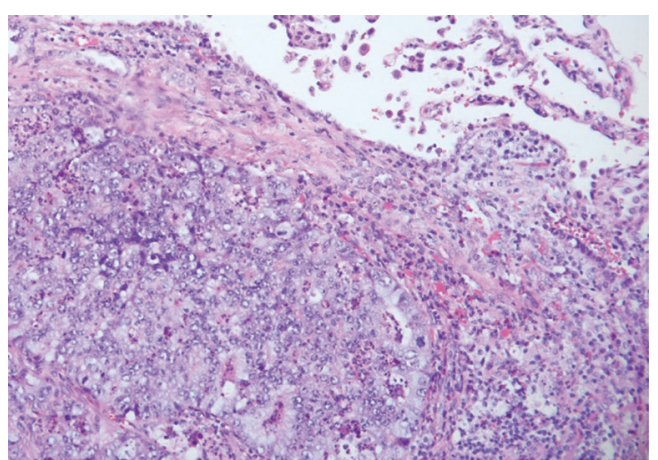

Figure 4 The nodule was confirmed as adenocarcinoma after surgery $(\mathrm{H} \& \mathrm{E}$ staining, $\times 200)$.

cavitary disease is the course of disease progression. In the present case, the patient had smoked for 45 years, and the chest CT showed slow progression of COPD. It is common for patients with a smoking history greater than 40 years to contract COPD or emphysema (8). Although the insidious progression of cavitary disease is typically benign, it is important to estimate the potential risk of malignancy upon the observation of bulla in patients with risk factors such as heavy smoking.

In conclusion, we present a rare case of lung adenocarcinoma with a thin-wall cavity, initially presenting as localized emphysema. Although rare, thin-wall cavitary lesions may pose a potential risk of malignancy in high-risk patients, and close follow-up is required.

\section{Acknowledgments}

Funding: This study is supported by the 1.3.5 Project for Disciplines of Excellence (ZYJC18009), West China Hospital, Sichuan University.

\section{Footnote}

Conflicts of Interest: All authors have completed the ICMJE uniform disclosure form (available at http://dx.doi. org/10.21037/tcr.2020.01.29). The authors have no conflicts of interest to declare.

Ethical Statement: The authors are accountable for all aspects of the work in ensuring that questions related to the accuracy or integrity of any part of the work are appropriately investigated and resolved. All procedures performed in studies involving human participants were in accordance with the Declaration of Helsinki (as revised in 2013). Written informed consent was obtained from the patient for publication of this manuscript and any accompanying images.

Open Access Statement: This is an Open Access article distributed in accordance with the Creative Commons Attribution-NonCommercial-NoDerivs 4.0 International License (CC BY-NC-ND 4.0), which permits the noncommercial replication and distribution of the article with the strict proviso that no changes or edits are made and the original work is properly cited (including links to both the formal publication through the relevant DOI and the license). See: https://creativecommons.org/licenses/by-nc-nd/4.0/.

\section{References}

1. Gadkowski LB, Stout JE. Cavitary pulmonary disease. Clin Microbiol Rev 2008;21:305-33.

2. Qi Y, Zhang Q, Huang Y, et al. Manifestations and pathological features of solitary thin-walled cavity lung cancer observed by CT and PET/CT imaging. Oncol Lett 2014;8:285-90.

3. Xue X, Wang P, Xue Q, et al. Comparative study of solitary thin-walled cavity lung cancer with computed tomography and pathological findings. Lung Cancer 2012;78:45-50.

4. Woodring JH, Fried AM, Chuang VP. Solitary cavities of the lung: diagnostic implications of cavity wall thickness. AJR Am J Roentgenol 1980;135:1269-71.

5. Watanabe Y, Kusumoto M, Yoshida A, et al. Cavity Wall Thickness in Solitary Cavitary Lung Adenocarcinomas Is a Prognostic Indicator. Ann Thorac Surg 2016;102:1863-71.

6. Watanabe Y, Kusumoto M, Yoshida A, et al. Surgically resected solitary cavitary lung adenocarcinoma: association between clinical, pathologic, and radiologic findings and prognosis. Ann Thorac Surg 2015;99:968-74.

7. Xue XY, Liu YX, Wang KF, et al. Computed tomography for the diagnosis of solitary thin-walled cavity lung cancer. Clin Respir J 2015;9:392-8.

8. Rabe KF, Watz H. Chronic obstructive pulmonary disease. Lancet 2017;389:1931-40.

Cite this article as: Cheng $\mathrm{J}$, Mei J, Pu Q, Liu L. Lung adenocarcinoma initially mimicking localized emphysema. Transl Cancer Res 2020;9(3):2074-2076. doi: 10.21037/ tcr.2020.01.29 